\title{
AS CONTRIBUIÇÕES DAS DISCUSSÕES SOBRE A CIÊNCIA FRENTE À IDEIA DE PESQUISA COMO ENSINO
}

\author{
THE DISCUSSIONS ON SCIENCE FRONT THE IDEA OF RESEARCH AS \\ TEACHING
}

Mateus de Souza Duarte ${ }^{1}$

ORCID iD: 0000-0002-7199-1652

Francisca Keila de Freitas Amoedo ${ }^{2}$

ORCID iD: 0000-0002-9052-8567

\section{RESUMO}

$\mathrm{O}$ ato de pesquisar é algo delicado que exige atenção, metodologia adequada e comprometimento científico, sobretudo, quando ocorre no exercício da docência. Assim sendo, o presente artigo objetiva "discutir as contribuições das discussões sobre a ciência em Gaston Bachelard para compreender os caminhos do docente frente à ideia de pesquisa como ensino e a figura do professor pesquisador, buscando compreender os caminhos do docente diante da pesquisa, no ato de ensinar. $\mathrm{O}$ manuscrito tratado na análise é de cunho qualitativo e bibliográfico, tendo como base Gaston Bachelard (1996; 1978), com o enfoque na construção do espírito científico e superação dos obstáculos "epistemológicos". Valemo-nos também de Lima e Kalhil (2016), Santos et al (2016), Dominguini e Silva (2010), Barcellos e Santos (2010), que em seus escritos se lançam nas ideias de Bachelard. Igualmente, caminhamos junto a Pedro Demo $(2004 ; 2010 ; 2011)$ os quais contribuem com a base teórica a respeito da ação docente e pesquisa.

Palavras-chave: Espírito Científico. Obstáculos Epistemológicos. Professor Pesquisador.

\begin{abstract}
The act of researching is something delicate, which requires attention, adequate methodology and scientific commitment, especially when it occurs in the exercise of teaching. Therefore, this article aims to "discuss the contributions of discussions on science in Gaston Bachelard to understand the ways of the teacher in the face of the idea of research as teaching and the figure of the teacher researcher, seeking to understand the ways of the teacher in the face of research, in act of teaching. The manuscript treated in the analysis is of a qualitative and bibliographic nature, based on Gaston Bachelard $(1996 ; 1978)$, with a focus on building the scientific spirit and overcoming the "epistemological" obstacles. We also used Lima and Kalhil (2016), Santos et al (2016), Dominguini and Silva (2010), Barcellos and Santos (2010), which in their writings are based on Bachelard's ideas. Likewise, we walked with Pedro Demo $(2004 ; 2010 ; 2011)$, who contributes to the theoretical basis of teaching and research.
\end{abstract}

\footnotetext{
1 Mestre em Educação e Ensino de Ciências na Amazônia (PPGEEC), pela Universidade do Estado do Amazonas (UEA). Membro do Grupo de Estudo e Pesquisa Educação em Ciências em Espaços Não-Formais (GEPECENF/UEA). Graduado em Licenciatura em Pedagogia e Especialista em Gestão e Coordenação Pedagógica. Professor Voluntário no Centro de Estudos Superiores de Parintins (CESP), da Universidade do Estado do Amazonas (UEA). Estr. Odovaldo Novo, 4768 - Djard Vieira, Parintins - AM, CEP: 69152-510. Email: mateus_duarte22@hotmail.com.

${ }^{2}$ Doutoranda do Programa de Pós-Graduação em Educação em Ciências e Matemática (PPGECEM) na Rede Amazônica de Educação em Ciências e Matemática (REAMEC). Mestre em Educação e Ensino de Ciências da Amazônia (PPGEEC), pela Universidade do Estado do Amazonas (UEA). Possui graduação em Pedagogia (UNIALSSELVE) e graduação em Normal Superior pela Universidade do Estado do Amazonas (UEA). Pósgraduação em Psicopedagogia, Ed. Inclusiva e LIBRAS. Atualmente é professora efetiva no Centro de Estudos Superiores de Parintins (CESP), da Universidade do Estado do Amazonas (UEA). Estr. Odovaldo Novo, 4768 Djard Vieira, Parintins - AM, CEP: 69152-510. E-mail: keilamoedo@ hotmail.com.
} 
Keywords: Scientific Spirit. Epistemological obstacles. Researcher Teacher.

\section{INTRODUÇÃO}

A sociedade mudou, novos costumes e maneiras comportamentais foram impostas por essas mudanças, tanto na gerência familiar, laboral e escolar. Na escola, novas metodologias de ensino buscam espaço na educação formal e, o docente, para não sucumbir no exercício da profissão, deve se atualizar diante das inovações contemporâneas. Uma das alternativas trazidas na atualidade para o campo educativo é o ensino por meio da pesquisa. A iniciativa torna-se mais interessante no processo de ensino e aprendizagem na medida em que se insere o discente em um universo de descobertas contextualizadas com os conteúdos ministrados. Tais procedimentos metodológicos buscariam estimular a curiosidade natural dos alunos, os quais estariam protagonizando o processo de aprendizagem por meio da resolução de problemas, com perguntas e questionamentos direcionados pelo professor. A proposta de ensino por meio da pesquisa é oportuna, nesse sentido, frente aos percursos metodológicos necessários ao docente.

O professor diante das inovações metodológicas que devem permear o processo de ensino e aprendizagem, no nosso pronto de vista, deve se lançar à pesquisa para ensinar e aprender. Caminhar junto à pesquisa científica, para um iniciante, é enveredar por um labirinto de interrogações, sobretudo, em sala de aula. Diante à essas assertivas, o presente escrito busca "discutir as contribuições das discussões a respeito da ciência em Gaston Bachelard, para compreendermos os caminhos do docente frente à ideia de pesquisa como ensino", voltados para a superação dos obstáculos na construção do espírito científico caracterizados no caminho da pesquisa e buscando pontuar conexões entre o pensamento de Bachelard e o exercício da docência através da pesquisa como técnica científica de ensino e aprendizagem.

A construção do espírito científico e seus conceitos, a superação dos percalços da pesquisa - obstáculos epistemológicos - os entraves na vida do professor pesquisador e a conjuntura que limitam o pensamento científico são elencados nesse trabalho.

Caminhamos junto à Gaston Bachelard $(1978$; 1996) para construir a base teórica, nutrindo nossas ideias sobre o espírito científico e superação dos obstáculos, conceituados pelo autor como "epistemológicos". Seguimos com Lima e Kalhil (2016), Santos et al (2016), Dominguini e Silva (2010), Barcellos e Santos (2010), os quais em seus escritos se lançam às ideias de Bachelard para enrijecer os próprios estudos e, também, o nosso. Pedro Demo (2004; 2010; 2011) sustenta a base sobre a qual é defendida o professor como pesquisador, nos reportando a ideia de ensino por pesquisa. 


\section{REFERENCIAIS TEÓRICOS}

\subsection{O que defendia Gaston Bachelard?}

Bachelard é um teórico com algumas obras publicadas e conceituadas no universo acadêmico, todavia, nos debruçamos com maior ênfase na "a formação do espírito científico", de tradução de 1996 e "o novo espirito científico" de 1978. Apesar de Bachelard ter faleceu em 1962, seus estudos permanecem atuais e relevantes para o meio científico, principalmente, para a compreensão dos problemas científicos contemporâneos, no que diz respeitos às discussões sobre pesquisas e ensino.

Na obra sob análise, a ideia principal defendida por Bachelard é que no futuro o conhecimento se baseará na negação do conhecimento atual, nos ensinam Barcellos e Santos (2010). Bachelad (1996, p. 18) menciona que "quando o espírito se apresenta à cultura científica, nunca é jovem. Aliás, é bem velho, porque tem a idade de seus preconceitos. Aceder à ciência é rejuvenescer espiritualmente, é aceitar uma brusca mutação que contradiz o passado". Ainda "O novo espírito científico" objetiva ultrapassar os obstáculos epistemológicos que impedem a ciência de progredir, criticando as concepções que dão continuidade a história das ciências, introduzindo a categoria de ruptura para assinalar a dupla descontinuidade histórica e epistemológica que nela se verifica.

O conhecimento não é estático e acabado. E isso faz com que surjam novas ideias e descobertas, uma vez que, se o conhecimento fosse um todo acabado, não haveria possiblidades para retificações sobre uma "verdade" que em um momento histórico, se dizia verdadeira longe de qualquer contradição, como nos diz o próprio Bachelard (1996, p. 14) que "para confirmar cientificamente a verdade, é preciso confrontá-la com vários e diferentes pontos de vista". Assim, "o ponto de partida da atividade científica não pode convencer plenamente" (BACHELARD, 1978, p. 92). Uma problemática nunca é solucionada por completo, ela sempre, exclamamos, será passiva de novos questionamentos. Faz-se necessária, por isso, uma constante retificação dos conhecimentos já postos como verdade, pois somente nesse movimento o progresso científico poderá prosperar (IBIDEM, 1996).

Conceitos de "conhecimento", de "cultura científica", de "ruptura", e por último o de "conhecimento de conceito científico" são salutares e inerentes à construção de novos conhecimentos surgidos após se burilar os saberes ditos espúrios, ou seja, os saberes do senso comum. Segundo Almeida (2010, p. 141) a ciência possui "um conjunto de condições que lhe garante permanecia, circulação e refinamento [...] e a ela que se recorre como a referência autorizada para a formação do cidadão". 
O conhecimento "verdadeiro" nunca se mostra de primeira e esclarecido, diz Bachelard (1996). O real nunca é "o que se poderia achar, mas é sempre o que se deveria ter pensado [...] $\mathrm{o}$ ato de conhecer dá-se contra um conhecimento anterior, destruindo conhecimentos mal estabelecidos" (BACHELARD, 1996, p. 17). Pela assertiva anterior, podemos inferir é um erro pensar que se conhece algo apenas por se ter vislumbrado uma vez. No entanto, muito pelo contrário, o aprendizado vem com a prática contínua e com a observação cuidadosa dos fatos. Assim:

Se não nos acautelarmos, seremos dominados pela tendência simplesmente racional. O nosso racionalismo simples entrava o nosso racionalismo completo e, sobretudo, o nosso racionalismo dialético. Eis uma prova de como as filosofias mais sãs, como o racionalismo newtoniano e kantiano, podem em determinadas circunstâncias, constituir um obstáculo ao progresso da cultura (BACHELARD, 1978, p. 26).

$\mathrm{O}$ autor nos aconselha a caminhar cautelosamente frente às descobertas científicas para não cairmos no modismo simplistas das descobertas, de modo a não sucumbirmos à simples opiniões demasiadas, pois:

a ciência a, tanto por sua necessidade de coroamento como por princípio, opõe-se absolutamente à opinião. Se, em determinada questão, ela legitimar a opinião, é por motivos diversos daqueles que dão origem à opinião; de modo que a opinião está, de direito, sempre errada. A opinião pensa mal; não pensa: traduz necessidades em conhecimentos (BACHELARD, 1996, p. 18).

Desse modo, pode-se contribuir para melhor entendimento, Almeida (2010, p. 140), quando esclarece que "a ciência como instituição é uma expressão da cultura, uma construção humana, uma forma particular de diálogo entre cientistas e acadêmicos e destes com os fenômenos que procuram explicar, entender, modificar". A “cultura científica" também é pontuada por Bachelard (1996, p. 17) como um "estado de mobilização permanente, o qual substitui o saber fechado e estático por um conhecimento aberto e dinâmico, dialetizar todas as variáveis experimentais, oferecer enfim à razão razões para evoluir". Ousamos dizer, que todo conhecimento é passivo de objeções e retificações. Tudo deve ser problematizado, de modo a levantarmos novas reflexões. Uma vez que o conhecimento não é perene, logo é algo a ser posto em xeque, pois o homem é um ser que anseia por mudanças e transformações que possam subjugar o pretérito afim de propor novas ideias retificadas (BACHELARD, 1996).

Segundo Lima e Kalhil (2016), a "ruptura" discutida por Bachelard, está ligada aos anteriores e julgamos pertinente, pois o autor reforça que a observação primeira é repleta de imagens, é natural e fácil, entretanto destaca a necessidade de romper e abandonar o 
empirismo imediato e não oferecer uma continuidade entre observação e experimentação (BACHELARD, 1996). Pensamos que essa ruptura é uma separação dos saberes do senso comum para um saber mais depurado, mais científico, a partir das problematizações dos fatos.

Ainda, o pesquisador não deve sucumbir às imagens primeiras, uma vez, que para Bachelard (1996) elas são falhas, falsas e absolutas ao ponto de não possibilitar problematizações dos fatos, assim:

\footnotetext{
Não se pode basear nada na opinião: antes de tudo, é preciso destruí-la. Ela é o primeiro obstáculo a ser superado. Não basta, por exemplo, corrigi-la em determinados pontos, mantendo, como uma espécie de moral provisória, um conhecimento vulgar provisório. O espírito científico proíbe que tenhamos uma opinião sobre questões que não compreendemos, sobre questões que não sabemos formular com clareza. Em primeiro lugar, é preciso saber formular problemas (BACHELARD, 1996, p. 18).
}

Sob a perspectiva Bachelariana, o "conhecimento científico" como consequência do pensamento científico, pode-se afirmar que corresponde a um fenômeno particular. Assim, é o agrupamento de aproximações sucessivas bem ordenadas, como nos falam Lima e Kalhil (2016). A contextualização científica, nesse norte, precisa de uma série de conceitos em vias de aperfeiçoamento para chegar à dinâmica que pretendemos, para formar um eixo de pensamentos inventivos (BACHELARD, 1996).

Com base nos pressupostos aqui apresentados procuramos enunciar os conceitos de Bachelard levantando reflexões sobre conhecimento, cultura científica, ruptura e formação de conceitos que contribuem para compreendermos sua epistemologia no que se refere ao binômio professor pesquisador.

\subsection{A construção do espírito científico na pesquisa}

No decorrer da história muitos teóricos e epistemólogos mostraram, analisaram e buscaram compreender como ocorre certos aspectos do processo de produção do conhecimento, bem como sua apropriação pelos seres humanos (DOMINGUINI; SILVA, 2010). Sob a ótica de Bachelard, descobrimos que a partir das rupturas dos obstáculos epistemológicos o conhecimento é aflorado, (re)construído podendo ser retificado. Assim "A noção de obstáculo epistemológico pode ser estudada no desenvolvimento histórico do pensamento científico e na prática da educação" (BACHELAD, 1996, p. 21).

Segundo Lima e Kalhil (2016), as obras de Gaston Bachelard encontram-se em um contexto de revolução científica demarcada na história de três grandes períodos do pensamento 
científico: a) estado pré-científico "faz parte do século. Não é regular como o pensamento científico ensinado nos laboratórios oficiais e codificado nos livros escolares. Veremos que a mesma conclusão se impõe sob um ponto de vista ligeiramente diferente" (BACHELARD, 1996, p. 36). Antiguidade clássica, Renascimento e séculos XVI, XVII e XVIII; b) estado científico - fim do século XVIII, século XIX e início do século XX; c) novo espírito científico - iniciando em 1905, quando a relatividade de Einstein deforma conceitos primordiais que eram tidos como já fixados para sempre.

O pensamento científico para ser amadurecido precisa passar pelo processo da problematização, pois "proíbe que tenhamos uma opinião sobre questões que não compreendemos, sobre questões que não sabemos formular com clareza. Em primeiro lugar, é preciso saber formular problemas" nos expõe Bachelard (1996, p. 18), nos levando, de maneira singular, a refletirmos sobre a questão de opinar apenas pelo senso comum, sem considerar a dialetização dos fatos, uma vez que, "não se pode basear nada na opinião: antes de tudo, é preciso destruí-la. Ela é o primeiro obstáculo a ser superado" (IDEM, 1996, p. 18), pois "a primeira contradição é então, como sempre, o primeiro conhecimento" (BACHELARD, 1978, p. 13).

A formação do Espírito Científico caminha por três estados. O primeiro é o Estado concreto, o segundo é o Estado concreto-abstrato, e o terceiro é Estado abstrato, sedo que:

\begin{abstract}
$\mathrm{O}$ estado concreto, em que o espírito se entretém com as primeiras imagens do fenômeno e se apoia numa literatura filosófica que exalta a Natureza, louvando curiosamente ao mesmo tempo a unidade do mundo e sua rica diversidade. $\mathrm{O}$ estado concreto-abstrato, em que o espírito acrescenta à experiência física esquemas geométricos e se apoia numa filosofia da simplicidade. O espírito ainda está numa situação paradoxal: sente-se tanto mais seguro de sua abstração, quanto mais claramente essa abstração for representada por uma intuição sensível. O estado abstrato, em que o espírito adota informações voluntariamente subtraídas à intuição do espaço real, voluntariamente desligadas da experiência imediata e até em polêmica declarada com a realidade primeira, sempre impura, sempre informe (BACHELARD, 1996, p. 11-12).
\end{abstract}

Os atos que retardam a formação do espírito científico ocorrem como obstáculos dizem Dominguini e Silva (2010), ou seja, atos que provocam um congelamento e retrocesso no processo de evolução da ciência e de apropriação do próprio conhecimento. Pensando nisso, se torna evidente que devemos buscar sempre superar obstáculos, denominados como epistemológicos, que são conflitos não observados, causadores da regressão ou a estagnação do ato de conhecer, corrobora Santos et al (2016).

Um pensamento não científico é associado ao senso comum, de modo não ser um saber burilado, um saber esclarecido, se configurando em um obstáculo para a construção da ciência. 
Barcellos e Santos (2010), comentam que o senso comum é um dos obstáculos, a intuição primeira, a contradição, o pensamento generalizado, o matematismo demasiado vago, o conhecimento unitário e pragmático, a dogmatizarão, a impossibilidade de negação e o próprio cérebro, são fatores que podem retardar o a ruptura do pensamento comum, da opinião sem fundamento, sem problematização, para o conhecimento científico e a construção de um novo saber.

$\mathrm{Na}$ pesquisa científica as opiniões devem ser problematizadas para saírem do campo comum, pois "na ciência, tanto por sua necessidade de coroamento como por princípio, opõese absolutamente à opinião" (BACHELARD, 1996, p. 18). Pensamos que a mera opinião aqui mencionada é o que no vulgar, pode ser chamado de "achismo". Algo sem uma problematização, sem a consistência do argumento científico, uma vez que "um obstáculo epistemológico se incrusta no conhecimento não questionado" (BACHELARD, 1996, p. 19), isto é, não devemos palpitar sobre algo sem possuirmos argumentos científicos consistentes e maduros:

a primeira experiência ou, para ser mais exato, a observação primeira é sempre um obstáculo inicial para a cultura científica. De fato, essa observação primeira se apresenta repleta de imagens; é pitoresca, concreta, natural, fácil. Basta descrevê-la para se ficar encantado. Parece que a compreendemos. Vamos começar nossa investigação caracterizando esse obstáculo e mostrando que há ruptura, e não continuidade, entre a observação e a experimentação (BACHELARD, 1996, p. 25).

No campo da pesquisa as ideias primeiras para Bachelard (1996, p. 18), são "aquilo que cremos saber ofuscando o que deveríamos saber", de puro cunho comum, e devem ser abandonadas, para que a pesquisa ganhe mais robustez e rigor. As primeiras imagens surgem como viciosas, podendo levar ao erro e confundir um desavisado em seu caminho. Contudo, para sair desse círculo vicioso de impressões primeiras e problematizar, o pesquisador precisa ter conhecimentos, leituras mais aprofundadas, para então, questionar melhor com perguntas consistentes e significantes (DOMINGUINI; SILVA, 2010).

O conhecimento geral como obstáculo ao conhecimento científico também deve ser considerado na construção da pesquisa, ao passo ser a generalização universalizada das coisas:

há de fato um rigoroso prazer intelectual na generalização apressada e fácil. A psicanálise do conhecimento objetivo deve examinar com cuidado todas as seduções da facilidade. Só com essa condição pode-se chegar a uma teoria da abstração científica verdadeiramente sadia e dinâmica (BACHELARD, 1996, p. 69). 
O fracasso do processo científico, em geral, será sobremaneira o fracasso das experiências, uma vez que "alardeia-se o fracasso, quando o fracasso é evidente", diz Bachelard (1996, p. 300), criando uma nebulosa frente à construção do conhecimento científico. Lima e Kalhil (2016) comentam que se fazem necessárias a refutação e contradição do saber já dito como verdadeiro, possibilitando sua aplicação e reflexão.

O pesquisador deve perceber de maneira efetiva o amadurecimento de suas ideias no percurso da construção do conhecimento profissional, acadêmico e pessoal. Seguindo-se Bachelard (1996, p.19), "quando o conhecimento empírico se racionaliza nunca se pode garantir que valores sensíveis primitivos não interfiram nos argumentos”. Em decorrência desse sentido, o pesquisador precisa ter a noção do fracasso em sua pesquisa para não estagnar, no sentido de achar que suas ideias nunca serão refutadas e negadas, pois como ser humano, é e estará constantemente passivo ao erro:

descrito o fascínio da observação particular e colorida, vamos mostrar o perigo de seguir as generalidades de primeira vista, pois como diz tão bem d'Alembert, generalizam-se as primeiras observações no instante seguinte, quando não se observa mais nada. Vamos perceber assim o espírito científico entravado já na origem por dois obstáculos, de certa forma opostos. Será a ocasião de vermos o pensamento empírico numa oscilação cheia de tropeços e de conflitos, que acaba em desarticulação. Mas essa desarticulação torna possíveis movimentos úteis (BACHELARD, 1996, p. 25).

As generalidades das primeiras experiências aparentemente repletas de rótulos e verdades aparentemente já solucionadas que não precisam mais passar pelo crivo da problematização estagnam o pensar crítico e científico. Todavia, os fatos e a problematização devem, por assim dizer, estar em conúbio para que o conhecimento fecunde e cresça. $\mathrm{O}$ pesquisador deve questionar a si mesmo, questionar seus dados e fatos para não tropeçar nesses obstáculos científicos.

Em consonância com o exposto, levantamos a assertiva de que o pesquisador não deve se levar por meras falácias do cotidiano, mas sim pelos argumentos da ciência, uma vez que, apenas através dela ele poderá arrancar as escamas do comum para vislumbrar o cerne científico dos e nos fatos, de modo a obter perguntas e problemas que o ajudem a trilhar a senda da pesquisa.

\section{O PROFESSOR PESQUISADOR EM BACHELARD}

$\mathrm{O}$ ato de ensinar se distancia do lugar comum, ou de significar monotonia. Ensinar ainda é excitante e exerce um fascínio ao docente. Senão, se torna algo mecânico, sem brilho, sem 
protagonismo e desmotivador. No entanto, se faz necessário abrir mão de costumes e atividades mirradas, corrosivas, insípidas ao conhecimento científico. Deve-se, consequentemente, ensinar de maneira contextualizada, primando pelo conhecimento prévio do aprendiz, distanciando-se das atividades conteudistas e departamentalizadas, cujas disciplinas versam separadamente, impingidas pelo paradigma dito tradicional da educação: o repasse de conhecimento e aceitação passiva do estudante.

Ensinar pela pesquisa e de maneira reflexiva são dois paradigmas emergentes que pairam sobre a formação dos professores na atualidade. Portanto, diz Bachelard (1996) que devemos ultrapassar os obstáculos que impedem a construção e retificação do conhecimento científico, ou seja, o educar pela pesquisa impulsionaria o professor a expurgar os obstáculos, saberes não científicos, e dizer "não" às práticas risíveis ao ensino, como utilizar por anos a fio o mesmo plano de aula, as mesmas atividades de colagens, dos mesmos textos retirados dos mesmos livros, com suas páginas amareladas pelos anos. Na educação formal, os obstáculos epistemológicos, geralmente:

[...] impedem o aluno de compreender o conhecimento científico. A aprendizagem de um novo conhecimento é um processo de questionamento de nossas concepções prévias, a partir da superação dos obstáculos epistemológicos existentes nesses conhecimentos (LOPES, 1999, p. 128).

É preciso se abster de antigas práticas viciosas na educação, como a ideia obsoleta de "transferência" de conhecimento, uma educação bancária, como diria Freire (2011). O professor como educador deve caminhar para longe da estagnação, de pensar que não precisa se renovar, de estudar, de aprender novas maneira de ensinar. Precisa-se "compreender com Bachelard a noção de ruptura no conhecimento científico é assumir uma nova forma de compreender toda a história do conhecimento científico" (LOPES, 1999, p. 130).

Necessita-se hoje, por esse prisma, de práticas docentes que interajam com o conhecimento prévio do estudante, uma vez que as "pesquisas na área de Ensino de Ciências debatem a necessidade de valorizarmos as concepções prévias dos alunos" (LOPES, 1999, p. 137). Portanto, é edificante concentrarmos técnicas que arrebatem a atenção dos alunos e os incentivem a aprender. Barroso e Pinto (2017, p. 246) dizem que:

A educação passa a ser assim um trabalho ativo em que o conhecimento é construído em uma via de mão dupla, entre sujeito e objeto. Cabe ao educador ajudar ao educando, mediante a construção do conhecimento científico, aprender a eliminar as primeiras impressões irrefletidas, oriundas do primeiro contato com seu objeto de estudo. Essas primeiras impressões espontâneas são obstáculos que impedem a construção objetiva do conhecimento - finalidade do saber científico. 
Como consequência, há uma necessidade imperiosa de ultrapassarmos a barreira dos obstáculos da experiência primeira e do conhecimento geral, na educação, no que concerne o ensino e aprendizagem dos alunos. Todavia, é preciso, a priori, que se reconheça a existência de tais obstáculos, pois segundo Bachelard (1996, p. 23):

Na educação, a noção de obstáculo pedagógico também é desconhecida. Acho surpreendente que os professores de ciências, mais do que os outros se possível fosse, não compreendam que alguém não compreenda. Poucos são os que se detiveram na psicologia do erro, da ignorância e da irreflexão.

Para Bachelard, no momento histórico que postulou sua tese, os professores de ciências desconheciam ou negavam a existência de obstáculos no ensino, se configurando em um obstáculo também. Não se pode sanar um problema se a sua presença é negada ou ignorada. Bachelard (1996, p. 23):

\begin{abstract}
Os professores de ciências imaginam que o espírito começa como uma aula, que é sempre possível reconstruir uma cultura falha pela repetição da lição, que se pode fazer entender uma demonstração repetindo-a ponto por ponto. Não levam em conta que o adolescente entra na aula de física com conhecimentos empíricos já constituídos: não se trata, portanto, de adquirir uma cultura experimental, mas sim de mudar de cultura experimental, de derrubar os obstáculos já sedimentados pela vida cotidiana.
\end{abstract}

Bachelard afirma que os professores de sua época se lançavam a meras repetições conteudistas e reducionistas de assuntos já elaborados por terceiros, e que essa prática facilitava o avanço de falhas da cultura científica, o que na maioria das escolas ainda é frequente. Negar que há uma ossificada cultura de repetições de materiais, se valendo do uso dos mesmos planos de aula na prática educativa ano após ano é empobrecer e enferrujar a possibilidade de novas ideias, com novas metodologias para o ensino. Para Barroso e Pinto (2017, p. 246):

\footnotetext{
No que tange ao ensino de ciências em sua relação com a formação de professores, defendemos que, para que tenhamos uma ciência viva, temos que igualmente ter uma educação científica fundamentada em uma epistemologia que entenda o fazer científico como algo dinâmico, reconstruído diuturnamente com base na crítica racional. A educação deve ser dialética, no sentido que Bachelard dá a este conceito, ou seja; a educação deve ser feita pela apresentação de ideias e pelo estímulo a crítica das ideias apresentadas.
}

Hoje, com os avanços tecnológicos, quando as informações em todos os campos do conhecimento científico estão acessíveis com apenas um click no aparelho celular, é salutar abordar os assuntos em sala de aula da maneira mais atraente possível, capturando a atenção dos alunos, bem como despertando à curiosidade dos mesmos. Segundo Freire (2011), "quem ensina aprende ao ensinar e quem aprende ensina ao aprender”. Por conseguinte: 
[...] todo professor deve pensar em sua formação como contínua, na medida em que entenda o conhecimento como algo provisório e sempre reconstruído. É preciso aprender a identificar os obstáculos que se impõem a construção do conhecimento, sendo que, um dos principais obstáculos a ser superado é o da certeza do saber. $\mathrm{O}$ ato de ensinar deve ser ao mesmo tempo, um ato de aprender, de renovação do espírito científico e da formação de uma racionalidade aberta (BARROSO; PINTO, 2017, p. 146).

Nesse raciocínio, pensar em uma formação de professores para o ensino de ciências nos remete ao conceito de Ciência, do professor como pesquisador e no ensino por pesquisa. Para Almeida (2010, p. 140) a ciência "é uma expressão da cultura, uma construção humana, uma forma particular de dialogar entre os cientistas e acadêmicos e destes com os fenômenos que procuram explicar, entender, modificar”. Ainda, existem três passos inerentes à ciência:

O primeiro traço característico é de que a ciência é uma visão da realidade: a ciência é uma representação abstrata, sob a forma de conceitos, que se apresenta, com razão, como uma representação, não como um reflexo, do real. Segundo, a ciência visa a objetos para descrever e explicar, e não para agir, como num grande jogo do conhecimento. Terceiro, a ciência se preocupa com critérios de validação. Contudo, não se trata de uma validação pelo experimento: a verificação de um fato científico - que por ser científico já é uma construção — depende de uma interpretação ordenada, dentro de uma teoria explícita. Esses traços característicos nos levam a procurar analisar no que consiste a ciência, questão que pode ser aprofundada dentro da perspectiva de uma epistemologia histórica, como a de Gaston Bachelard (LOPES, 1999, p. 109).

Para Prigogine (2001, p. 15) “a ciência une os povos”. Segundo Chassot (2007) a ciência é uma construção dos homens e mulheres para melhor entender o mundo em que vivem. Santos (2010, p. 24) diz que "ao contrário da ciência aristotélica, a ciência moderna desconfia sistematicamente das nossas experiências imediatas. Tais evidências, que estão na base do conhecimento vulgar, são ilusórios". "A ciência não é mais que um modo de conhecer a realidade. Segundo esse modo, o essencial não é o que sabemos, mas como chegamos a sabêlo" (COLOMBEK, 2009, p. 17). Por sua vez, para Demo (1985, p. 20) “a ciência entende-se como processo de desmitologização e dessacralização do mundo, em favor da racionalidade natural, supondo-se uma ordem das coisas dada e mantida". Para Bachelard (1978, p. 91) "a ciência é um produto do espírito humano, produto conforme às leis de nosso pensamento e adaptado ao mundo exterior".

A ciência como construção humana é passível de refutações, tal como postula Bachelard (1996), uma vez que o conhecimento não é um axioma, como diz Japiassu (1992, p. 68) “o conhecimento é, por essência, uma obra temporal”, que depende do momento, história e filosofia que quem o produz. Contudo, ainda em Bachelard (1978, p. 92) "a ciência cria com 
efeito uma filosofia. O filósofo deve, portanto, tornar flexível sua linguagem para traduzir o pensamento contemporâneo em sua versatilidade e mobilidade". O conhecimento deve ser flexibilizado na sua maneira de ser repassado, porém não deixando seu rigor natural, possibilitando assim que o aprendiz possa compreendê-lo e isso, em nossa perspectiva, é função do professor, dentro do campo do ensino por pesquisa.

Historicamente, o paradigma do professor pesquisador tem suas raízes na Inglaterra, no século passado, quando emerge nos anos de 1960, nas chamadas secondary modern schools, nos informa Fagundes (2016). No entanto, para Carvalho:

A primeira grande influência para a Prática de Ensino foi trazida pelas teorias construtivistas, quando estas identificaram o indivíduo como o construtor de seu próprio conhecimento e descreveram o processo de construção desse conhecimento, chamando atenção tanto para a continuidade como para a evolução desse processo (CARVALHO, 1992, p. 47).

Um dos apontamentos trazidos pelo construtivismo condiz como o fato de o aluno não pode ser considerado uma tábua rasa, mas um ser cognoscente que cria e recria. Além disso, traz de seu convívio diário, saberes para a sala de aula.

\begin{abstract}
A descoberta de que os alunos trazem para as salas de aula conceitos estruturadas, com toda uma lógica própria e coerente e um desenvolvimento causal que é fruto de seus intentos para dar sentido às atividades cotidianas, mas, diferente da estrutura e da lógica usadas na definição científica desse conceito, abalou o ensino, que tinha como pressuposto que o aluno era uma tabula rasa, ou seja, ele não sabia nada sobre o que pretendíamos ensinar (CARVALHO, 1992, p. 48).
\end{abstract}

Educar pela pesquisa se distingue entre dois princípios: o científico e o educativo. Para Demo (2010) calçado do método científico a pesquisa visa à construção do conhecimento. Fazer pesquisa significa romper fronteiras, sempre levantando perguntas sobre o que já está posto, a partir de problematizações contínuas. Como princípio educativo retorna ao apelo formativo. Então, para Demo (2011, p. 7) educar pela pesquisa perpassa por 4 (quatro) pressupostos:

1) a convicção de que a educação pela pesquisa é a especificidade mais própria da educação escolar e acadêmica; 2) o reconhecimento de que o questionamento reconstrutivo com qualidade formal e política é a cerne do processo de pesquisa; 3 ) a necessidade de fazer da pesquisa atitude cotidiana no professor e no aluno; 4) a definição de educação como processo de formação da competência histórica humana.

A sala de aula é o laboratório do professor, diz Pimenta (1999), porém, acrescentamos que não apenas a sala de aula, mas todo espaço educativo podem e devem ser considerados, sob alguns aspectos científicos, como laboratórios, a saber a horta, quadra esportiva, refeitório, etc... outros espaços em que a educação científica ocorre. Todavia, geralmente são usados de maneira 
equivocada, ou seja, para o simples ato frígido de repassar conteúdos, sem materiais e inovação nas atividades com os alunos.

Segue-se uma rotina-leitura, oração, comentários, atividades sem contexto, alunos sentados e calados ouvindo, atividades advindas da internet já elaboradas, escrita no quadro e leituras em conjunto e o aluno passivo. Conhecimentos generalizados e sem propriedade do que se ensina, o que para Bachelard (1996) são os obstáculos do conhecimento geral e da opinição, que são vazias, frageis, fugaz e efêmeras, uma vez que são má reformuladas, sem problematizaões e critérios científicos. Uma realidade de muitas salas de aula, a qual deveria ser o lugar de (re)construção e (re)descoberta de conhecimentos, pois:

[...] que os alunos não abandonam facilmente as suas explicações espontâneas, mesmo quando submetidos a um ensino, e vieram a contribuir de maneira decisiva para a queda de uma concepção de ensino baseada na transmissão de conhecimento e para o estabelecimento de como seria em sala de aula um ensino que procura criar condições para que o aluno vá-se aprimorando do conhecimento socialmente elaborado (CARVALHO, 1992, p. 51).

Segundo Bachelard (1996, p. 14) "para confirmar cientificamente a verdade, é preciso confrontá-la com vários e diferentes pontos de vistas". É preciso ultrapassar a ideia ossificada da transmissão de conhecimento, da passividade do aluno e do professor como aquele que apenas ensina e detentor absoluto do saber, uma vez que, tais concepções já não cabem em nossos dias. É necessário implementar a inovação em sala de aula:

\footnotetext{
Logo, toda cultura científica deve começar, como será longamente explicado, por uma catarse intelectual e afetiva. Resta, então, a tarefa mais difícil: colocar a cultura científica em estado de mobilização permanente, substituir o saber fechado e estático por um conhecimento aberto e dinâmico, dialetizar todas as variáveis experimentais, oferecer enfim à razão razões para evoluir (BACHELARD, 1996, p. 24)
}

É mister o rompimento do saber estático, das páginas amareladas dos cadernos de anos de anotações, dos planos de aula que ano após ano se repetem, sem quaisquer alterações. Demo (2004) diz que a profissão do professor é algo estratégico, como sendo aquele que cuida da aprendizagem do aluno, pois "professor não é quem dá aula" (IBIDEM, 2004, p. 13), senão aquele que estimula a curiosidade científica. Portando, ser professor é:

Professor é quem, estando mais adiante no processo de aprendizagem e dispondo de conhecimento e práticas sempre renovados sobre aprendizagem, é capaz de cuidar da aprendizagem na sociedade, garantindo o direito de aprender. Professor é o eterno aprendiz, que faz da aprendizagem sua profissão (DEMO, 2004, p. 11). 
A profissão de 'ser' professor segundo Nóvoa (2009) perpassa por uma incumbência ontológica, de modo que o mesmo deve acreditar na educação como o caminho para um bem maior e no aluno como quem caminha em direção a esse bem. Todavia, há uma imperativa compreensão de que para tal fato prosseguir, o professor deve se desfazer de certos obstáculos no processo de ensino, como o da generalização das ideias, das opiniões marinadas de senso comum, sem o aprofundamento e domínio necessários dos conteúdos de suas disciplinas, assim Bachelard (1996, p. 24) comenta que:

Tais observações podem, aliás, ser generalizadas: são mais visíveis no Ensino de ciências, mas aplicam-se a qualquer esforço educativo. No decurso de minha longa e variada carreira, nunca vi um educador mudar de método pedagógico. O educador não tem o senso do fracasso justamente porque se acha um mestre. Quem ensina manda. Daí a torrente de instintos.

Precisa-se compreender que ensinar não é um monólogo. Ensinar é um diálogo entre os muitos conhecimentos já existentes e também entre os que irão surgir. Para Bachelard (1996, p. 24) “educador e educando merecem uma psicanálise especial”. Segundo Almeida (2010, p. 82):

O diálogo entre as disciplinas e as áreas do conhecimento científico, pautada pela suspensão dos pontos de vistas individuais, é um dos pontos de partida para inaugurar outros horizontes do conhecimento, horizontes menos ossificados, mais flexíveis, complexos.

No momento histórico em que vivemos, quando a educação formal é rechaçada e ridicularizada, o professor deve se lançar a novas metodologias para não sucumbir na carreira docente. Para Demo (2010, p. 19) “a pesquisa como princípio educativo proporciona a expectativa da cidadania ancorada em pesquisa ou produção própria de conhecimento, possibilitando a combinação de educação e ciência”. Ser professor é possibilitar a aprendizagem de alunos, porém, Demo (2010) aponta “cuidados" nessa empreitada entre ensino e pesquisa:

1) não se deve separar os processos, pois a educação deve estar dentro da pesquisa e a pesquisa entro da educação. 2) saber começar pelo começo, pois os alunos produzem conhecimento, mas tudo no tempo deles. 3) não se deve banalizar a pesquisa., facilidade, farsantes, encurtando caminhos. 4) não adotar pieguices pedagógicas, como deixar de avaliar o aluno para que o mesmo não desanime, de modo que o aluno tem total direito de aprender e não se empurrado de qualquer modo. 5) embora nos primeiros anos se acentue naturalmente face pedagógica, mesmo assim, ela precisa ser apresentada em termos metodológicos adequados, dentro do que se imagina ser hoje "educação cientifica" (DEMO, 2010, p. 23-24). 
Pesquisar envolve muito mais que pedir ao aluno para "navegarem" na internet em busca de algo. Pesquisar envolve métodos e técnicas, com observações e anotações atentas dos fenômenos imbuídos por uma pergunta/questionamento. Barros e Lehfeld (2012, p. 29) define a pesquisa como "o esforço dirigido para a aquisição de um determinado conhecimento, que propicia a solução de problemas teóricos, práticos e/ou operativos”.

Faz-se necessário ultrapassar os obstáculos inerentes ao fazer científico. Demo (2010) aponta 4 (quatro) condições para que a educação científica obtenha impacto estrutural e social. A primeira e, basilar condição, se volta à construção de "outras estratégias pedagógica", que não sejam adestrativas ou reprodutivas. A segunda se volta à reforma da formação docente, que produção pesquisas e literaturas científicas. A terceira reporta-se a transformação da escola em laboratório de pesquisa e produção de conhecimento, de modo que muitos professores ainda demonstram ter dificuldades no processo de fazer pesquisa em sala de aula. A quarta, quiçá, seja a mais complicada de ser executada, é a condição de transformar alunos em pesquisadores (DEMO, 2010).

Ser professor pesquisador na ótica de Fagundes (2016) perpassa por conhecer os conceitos e técnicas científicas, como também considerar as experiências dos alunos. Pois segundo Gengnagel e Pasinato (2012) existe um consenso na literatura educacional de que a pesquisa é um elemento essencial na formação profissional do docente. Pesquisar deve ser uma atividade inerente ao professorado:

De fato, as interpretações dos conceitos de professor pesquisador têm sido as mais variadas: para alguns, formar o professor pesquisador significa levar o futuro docente a realizar um trabalho prático ou uma atividade de estágio, que envolve tarefas de coleta e de análise de dados. Para outros, significa levar os futuros professores a desenvolver e implementar projetos ou ações nas escolas. E há ainda os que se valem do prestígio associado à pesquisa para divulgar essa ideia como um novo selo, um modismo ou uma marca de propaganda (GENGNAGEL; PASINATO, 2012, p. 55).

Pesquisar para ensinar ou ensinar pela pesquisa deve-se ou deveria estar na veia do professor, configurando-se em sua identidade enquanto guarnecedor da aprendizagem. Percalços sempre irão existir em quaisquer profissões, porém, cabe então o reconhecimento de sua existência e a mais adequada solução, para que o progresso ocorra, e a educação, o ensino, a aprendizagem não se diferem dessa cabal realidade. 


\section{CONSIDERAÇÕES}

O texto buscou apresentar e refletir a respeito de contribuições das discussões sobre a ciência frente ao pressuposto de pesquisa atrelada ao ensino, bem como o professor pesquisador. Discorremos a respeito da construção do espírito científico e seus conceitos, na busca da superação dos obstáculos epistemológicos, que dificultam a carreira de pesquisador e limitam o pensamento científico.

Buscou-se caminhar no sentido de refletir quais vícios de meras opiniões sem a comunhão com argumento científico devem ser abandonados. As opiniões infundadas, as experiências comuns, corriqueiras, que por um determinado tempo podem ser tomadas como verdade, mas que devem ser postas à mesa da problematização, para fecundar novo conhecimento, portanto um conhecimento científico e retificado.

Pensamos que frente às inúmeras metodologias que surgem no seio escolar, buscando auxiliar o professor no processo de ensino e aprendizagem, o ensino por pesquisa, a nosso ver, é interessante e bastante frutífero. Ensinar a partir da problematização de conteúdo, levando o aluno a refletir sobre seu próprio processo de aprendizagem e colocando-o como protagonista nesse contexto, com indagações, reflexões e questionamentos é salutar para uma prática de ensino mais efetiva.

As contribuições da pesquisa como ensino e a condição de professor pesquisador são salutares para no processo de ensino e aprendizagem neste novo cenário que se apresenta no espaço escolar, bem como social. A pesquisa atua como princípio educativo e formativo. E nesse contexto a escola deve se lançar ao desafio de usar a educação formal como espaço inicial de se fazer ciência, posto isto, se acentua a postura de se fazer ensino por pesquisa na tentativa de promover a formação voltada para potencializar os princípios científicos.

Acreditamos que o papel do professor é de elementar importância dentro do processo de ensino e sem o qual o ensino se torna eivado. A educação é uma engrenagem e o professor é uma peça estratégica e basilar para o bom funcionamento. Não estamos fazendo alusão à educação mecânica, muito pelo contrário, estamos dizendo que dentro de um sistema educativo, o professor ainda é uma das peças chave para o esclarecimento dos conteúdos e para que a aprendizagem se realize a contento.

Este artigo faz parte de uma futura construção ampliada acerca da temática dos pressupostos de Bachelard para a educação científica. Neste sentido foi necessário iniciar de compreensões básicas fundamentais para novos horizontes serem alcançados. Tendo sido 
atingido os objetivos propostos, espera-se que a leitura proporcione novas compreensões e que estimule aspectos reflexivos no âmbito escolar, principalmente, entre formadores.

\section{REFERÊNCIAS}

ALMEIDA. M. C. Complexidade, saberes científicos, saberes da tradição. São Paulo: Editora Livraria da Física, 2010.

BACHELARD, G. A complexidade essencial da filosofia científica. O Novo Espírito Científico. São Paulo: Abril Cultural, 1978. (Os pensadores).

BACHELARD, G. Formação do espírito científico: contribuição para uma Psicanálise do conhecimento. Rio de Janeiro: Contraponto, 1996.

BARCELlOS, A. C. K. SANTOS, A. In: $8^{\text {a }}$ Mostra Acadêmica. Desafios da Educação Superior no Novo Milênio. Piracicaba: UMIMEP, v. 516. p. 1-4, 2010. Disponível em: http://unimep.edu.br/noticias/8a-mostra-academica-473-trabalhos-sao-apresentados. Acesso em 20/12/2019.

BARROSO, M. A. SANTOS PINTO, T. J. Bachelard: a aprendizagem científica como ruptura. Educação Em Perspectiva, v. 8, n. 2, p. 232-249, maio/ago. 2017. Disponível em: https://doi.org/10.22294/eduper/ppge/ufv.v8i2.855. Acesso em 20/11/2019.

BARROS, A. J. P; LEHFELD, N. A. S. Projeto de pesquisa: propostas metodológicas. $21^{\circ}$. ed. Petrópolis, RJ: Vozes, 2012.

CARVALHO, A. M. P. Pesquisas em Sala de Aula: Um Importante Fator na Formação do Professor. In: Revista Perspectiva 17, 1992, p. 47-57. Disponível em:

https://periodicos.ufsc.br/index.php/perspectiva/article/view/9148/10690. Acesso em 20/12/2019.

CHASSOT, A. A Ciência é masculina? Sim senhora. $3^{\text {a }}$ ed. São Leopoldo: Editora UNISINOS. 2007.

DEMO, P. Introdução à metodologia da ciência. -2. ed. --São Paulo: Atlas, 1985. UNISINOS. 2007.

DEMO. P. Professor do futuro e reconstrução do conhecimento. Petrópolis, RJ: Vozes, 2004.

DEMO. P. Educação e alfabetização científica. SP: Papirus, 2010.

DEMO. P. Educar pela pesquisa. -9. ed. Revista-Campinas, SP, 2011.

DOMINGUINI, L. SILVA, I. B. Obstáculos a Construção do Espírito Científico: Reflexões Sobre o Livro Didático. In: V CINFE. Congresso Internacional de Filosofia e Educação. Caxias do Sul - Rio Grande do Sul, 2010. Disponível em:

https://www.ucs.br/ucs/tplcinfe/eventos/cinfe/artigos/artigos/arquivos/eixo_tematico10/OBST 
ACULOS\%20A\%20CONSTRUCAO\%20DO\%20ESPIRITO\%20CIENTIFICO.pdf. Acesso em 10/11/2019.

FREIRE, P. Pedagogia da Autonomia: saberes necessários a prática educativa. São Paulo, Paz e Terra, 2011.

FAGUNDES, T. B. Os conceitos de professor pesquisador e professor reflexivo: perspectivas do trabalho docente. In: Revista Brasileira de Educação, v. 21 n. 65 abr.-jun. p. 281-298, 2016. Disponível em: https://doi.org/10.1590/S1413-24782016216516. Acesso em 20/12/2019.

GOLOMBEK, D. A. Aprender e ensinar Ciências: do laboratório à sala de aula e viceversa. -2 ed. São Paulo: Sangari do Brasil: Fundação Santillana, 2009.

JAPIASSU, H. F. Introdução ao pensamento epistemológico. Rio de Janeiro, F. Alves, 1992.

LIMA, A. C. S.; KALHIL, J. B. A Epistemologia de Gaston Bachelard e a Formação de Conceitos Científicos no Ensino de Ciências. In: Simpósio de Educação em Ciências na Amazônia. Manaus, 2016. Anais $6^{0}$ SECAM. Manaus, 2016.

LOPES, A. R. C. Conhecimento escolar: ciência e cotidiano- Rio de Janeiro: Ed. UERJ, 1999.

NÓVOA. A. Professores: Imagens do futuro presente. Lisboa: Educa, 2009.

SANTOS, E. C. A.; GADELHA, L.; AGUIAR, J. V. S.; COSTA, M. G. Considerações sobre a construção do Espírito Científico a partir da Formação Continuada de Professores. In: Simpósio de Educação em Ciências na Amazônia, Manaus, 2016. Anais $6^{0}$ SECAM. Manaus, 2016.

SANTOS, B. S. Um discurso sobre as Ciências. -7 ed. São Paulo: Cortez, 2010.

GENGNAGEL, C. L; PASINATO, D. Professor pesquisador: perspectivas e desafios. In: Revista Educação por Escrito - PUCRS, v.3, n.1, jul. 2012, p. 53-61. Disponível em: http://revistaseletronicas.pucrs.br/ojs/index.php/porescrito/article/view/11208/8146. Acesso em 19/12/2019.

PIMENTA, S. G. Formação de professores: identidade e saberes da docência. In: PIMENTA, S. G. (Org). Saberes pedagógicos e atividade docente. São Paulo: Cortez Editora, 1999.

PRIGOGINE, I. Carta às futuras gerações. In: Almeida, M. C; CARVALHO, E. A. (Org). Razão e paixão Ciência, Belém: EDUEPA, 2001.

Submetido em: 20 de dezembro de 2019.

Aprovado em: 06 de fevereiro de 2020. 